\title{
APUNTES SOBRE DERECHO PENAL DEL TRABAJO*
}

\author{
Claudio Palavecino Cáceres* \\ Universidad de Chile \\ CARLOS POBLETE JiMÉNEZ* \\ Universidad Central de Çhile
}

\section{INTRODUCCIÓN}

Como vislumbrara el maestro argentino MARIO DEVEALI, todas las disciplinas jurídicas se hallan vinculadas por un elemento común, y es que todas tienen necesariamente un sector represivo. Esto es lo que se denomina comúnmente actividad sancionadora, que no es exclusiva del Derecho penal; sanción como actividad jurídica se establece siempre como una necesaria consecuencia del incumplimiento normativo.

Dentro del sistema represivo laboral podemos distinguir tres ámbitos:

1) Poder disciplinario del empleador: asociado a su potestad normativa -artículo 153 CT- para regular: "las obligaciones y prohibiciones a que deben sujetarse los trabajadores, en relación con sus labores, permanencia y vida en las dependencias de la respectiva empresa o establecimiento".

Es un poder-deber puesto que las empresas, establecimientos, faenas o unidades económicas que ocupen normalmente 10 o más trabajadores permanentes "estarán obligadas a confeccionar un reglamento interno de orden, higiene y seguridad" -artículo 153 CT-.

Es un poder finalizado: "especialmente se deberán estipular las normas que se deban observar para garantizar un ambiente laboral digno y de mutuo respeto entre los trabajadores".

Es un poder normativo jurídicamente perfecto puesto que viene dotado de potestad sancionatoria: la infracción por el trabajador de las obligaciones que señale este reglamento pueden ser sancionadas por el empleador con amonestación verbal o escrita y multa de hasta el $25 \%$ de la remuneración diaria -artículo $154 \mathrm{~N}^{\circ} 10 \mathrm{CT}$-.

2) Derecho represivo administrativo laboral: el Libro V, Título II CT, art. 506 CT, "las infracciones a este Código y a sus leyes complementarias, que no tengan señaladas una sanción especial, serán sancionadas con multa...".

La función de fiscalizar el cumplimiento de la legislación laboral, ha sido atribuida a la Dirección del Trabajo -en adelante DT- por su estatuto orgánico -DFL N²2 1967-. Se la dota, además, de una potestad sancionatoria -art. 34 DFL N²-. Puede cursar multas administrativas $u$ ordenar la clausura de un establecimiento o una faena.

\footnotetext{
* Seguimos, parcialmente, las fuentes y el esquema que trazara OrTiz SCHINDLER, Enrique. El Derecho Penal Laboral. Tesis. Santiago: Universidad de Chile, Facultad de Derecho, 1982.

* Profesor del Departamento de Derecho del Trabajo y la Seguridad Social de la Facultad de Derecho de la Universidad de Chile.

* Profesor de Derecho del Trabajo y la Seguridad Social de la Universidad Central de Chile.
} 
3) Derecho penal del trabajo: El ordenamiento jurídico otorga la tutela penal a bienes jurídicos tutelados también por el orden laboral. Pero es Derecho penal "a secas." Como dice Guillermo Cabanellas, el Derecho penal laboral es un capítulo especial del Derecho penal común, ya que carece de substantividad propia y sus normas y sus principios son los mismos que integran dicho Derecho. Los delitos "laborales" pertenecen a la ciencia penal y estos no pueden ser interpretados con la técnica jurídica que regla el Derecho laboral -MARIO DEVEALI-.

Tanto el Derecho represivo administrativo laboral (2) como el Derecho penal del trabajo (3), son manifestaciones del ius puniendi estatal. No es posible establecer diferencias cualitativas entre ambos órdenes normativos. ¿Qué diferencia sustantiva hay entre la falta penal y la falta administrativa? Ninguna. Es relevante tenerlo presente, sobre todo, desde el punto de vista garantístico. El sistema de garantías sustantivas y adjetivas que tiene el ciudadano frente al Derecho penal debe aplicarse también al Derecho represivo administrativo laboral.

Hecha esta constatación, limịtaremos nuestro análisis al Derecho penal del trabajo.

\section{CONCEPTOS Y DELITOS}

a) Conjunto de normas jurídicas penales dirigidas a tutelar la economía pública a través de la discriminación de actividades que tienden a alterar arbitrariamente las relaciones entre el capital y el trabajo, así como el orden y la disciplina de este, con el consiguiente peligro o daño para la marcha normal de la producción -VANNINI-.

b) Conjunto de normas jurídicas penales, de carácter represivo, destinadas a defender, en primer término, el orden jurídico laboral público contra actividades individuales que alteren arbitrariamente ese orden -KROTOSCHIN-.

c) Ordenamiento jurídico relativo a las acciones $\mathrm{u}$ omisiones voluntarias sancionadas por la ley penal y que guardan relación con la actividad laboral -CABANELLAS-.

\subsection{DELitos CONTRA LA LiBERTAD DE TRABAjO}

La libertad de trabajo, bien jurídico protegido mediante esta figura, está reconocida en la Constitución Política de la República, en el art. $19 \mathrm{~N}^{\circ} 16$. Esta libertad tiene un carácter bifronte: ampara tanto al trabajador como al empleador. Su contenido esencial, determinado por el propio texto constitucional comprende, entre otras garantías, que "ninguna clase de trabajo puede ser prohibida". El mismo texto constitucional la limita: se puede prohibir trabajos que se opongan a la moral, a la seguridad o a la salubridad públicas, o que lo exija el interés nacional y una ley lo declare así.

\subsubsection{Prohibición arbitraria de un trabajo o industria lícitos}

El art. $158 \mathrm{~N}^{\circ} 2$ del Código Penal -en adelante CP- castiga al "empleado público que arbitrariamente: [...] $\mathrm{N}^{\circ}$ 2. Prohibiere un trabajo o industria que no se oponga a la ley, a las buenas costumbres, seguridad y salubridad públicas". 
a) Es un delito con sujeto activo calificado, puesto que castiga al "empleado público". Y de hecho, se encuentra dentro del Título V, del Libro II del CP "de los crímenes y simples delitos cometidos por empleados públicos en el desempeño de sus cargos". Para los efectos de este Título, el art. $260 \mathrm{CP}$ señala que "se reputa empleado todo el que desempeñe un cargo o función pública, sea en la administración central o en instituciones o empresas semifiscales, municipales, autónomas u organismos creados por el Estado o dependientes de él, aunque no sean del nombramiento del Jefe de la República ni reciban sueldo del Estado. No obstará a esta calificación que el cargo sea de elección popular".

b) Tanto el empleador como el trabajador son sujetos pasivos del delito, toda vez que ambos ostentan titularidad sobre el bien jurídico protegido.

c) Desde el punto de vista subjetivo, se requiere dolo directo ${ }^{1}$.

d) El tipo objetivo comprende un elemento normativo: la conducta típica -el prohibirdebe ser ejecutada "arbitrariamente", vale decir, sin habilitación legal, sin facultad expresa y específica, o estando facultado, pero sin morivo que justifique el ejercicio de la facultad. En esta conducta podría incurrir el funcionario de la Inspección del Trabajo que ordenara arbitrariamente la clausura de un establecimiento o de una faena. "Debe recordarse que la 'antisocialidad' del trabajo o industria, o su oposición a las buenas costumbres, seguridad y salubridad públicas, deben ser declaradas por ley, de acuerdo con la Constitución, y no queda tal factor al arbitrio del funcionario" 2 .

e) Pena: "sufrirá la pena de suspensión en sus grados mínimo a medio, si gozare de renta, y la de reclusión menor en su grado mínimo o multa de once a veinte unidades tributarias mensuales, cuando prestare servicios gratuitos".

\subsubsection{Impedimento del libre acceso al lugar, medios o elementos de trabajo}

En el contexto del Título III - “Delitos contra el Orden Público”- de la Ley 12.927 sobre Seguridad del Estado, el art. art. $6^{\circ}$ letra c) señala que comenten delito contra el orden público los que de hecho y por cualquier medio impidan o dificulten el libre acceso a las instalaciones, los medios o elementos empleados para el funcionamiento de servicios públicos o de utilidad pública o de actividades industriales, mineras, agrícolas, comerciales, de comunicación, de transporte o de distribución. Asimismo sanciona a los que inciten, promuevan o fomenten tales actos.

Es relevante destacar que algunos elementos de la conducta típica:

a) En relación con el sujeto activo, comprende tanto al instigador o promotor como al ejecutor de hecho. No existe un sujeto activo calificado, de modo que cualquier persona imputable puede incurrir en ella;

\footnotetext{
${ }^{1}$ Bullemore, V. y Mackinnon, J. Curso de Derecho Penal. Tomo III, Parte Especial. Santiago: LexisNexis, 2007, p.118.

${ }^{2}$ Etcheberry, A. Derecho Penal, parte especial. Tomo III. Santiago: Editorial Jurídica de Chile, 1997, p. 224.
} 
b) Es un tipo material o de resultado y, además, un delito de lesión, pues la acción debe concretarse en un determinado resultado típico y se exige una afectación real y no meramente potencial -peligro- del bien jurídico tutelado. En efecto, la acción debe concretarse el impedimento o dificultad de acceso a las instalaciones, medios o elementos productivos. Se establece figuras agravadas si, además, se diere muerte a alguna persona o se le infirieren lesiones graves o de otro tipo o si el hecho se ejecutare en tiempo de guerra.

c) Las instalaciones, medios o elementos afectados pueden referirse tanto servicios públicos o de utilidad pública como a actividades industriales, mineras, agrícolas, comerciales, de comunicación, de transporte o de distribución de naturaleza privada.

d) Pena: Las conductas tipificadas en la letra c) del artículo 6 de la ley 12.927, son sancionadas de conformidad a las disposiciones del artículo 7 inciso tercero, el cual establece las siguientes penas:

“...presidio mayor en su grado medio a presidio perpetuo, si se diere muerte a alguna persona o se le infirieren lesiones graves, y con presidio mayor en su grado máximo a presidio perpetuo, si el hecho se ejecutare en tiempo de guerra;

“...presidio mayor en su grado mínimo, si se infiere cualquiera otra lesión, y con presidio mayor en su grado medio si se ejecutare en tiempo de guerra;

“...presidio menor en su grado máximo a presidio mayor en su grado mínimo, en los demás casos, y con presidio mayor en su grado mínimo si el hecho se ejecutare en tiempo de guerra".

\subsection{DELITOS CONTRA EL PATRIMONIO}

\subsubsection{Delitos contra el patrimonio empresarial}

\section{A) El sabotaje industrial}

El mismo art. $6^{\circ}$ letra c) de la Ley 12.927 castiga a "los que inciten, promuevan o fomenten; o de hecho y por cualquier medio, destruyan, inutilicen, paralicen, interrumpan o dańen las instalaciones, los medios o elementos empleados para el funcionamiento de servicios públicos o de utilidad pública o de actividades industriales, mineras, agrícolas, comerciales, de comunicación, de transporte o de distribución..."

a) Comprende tanto al instigador o promotor como al ejecutor de hecho y no existe un sujeto activo calificado, de modo que cualquier persona imputable puede incurrir én ella;

b) Es un tipo material o de resultado y, además, un delito de lesión, pues la acción debe concretarse en un determinado resultado típico y se exige una afectación real y no meramente potencial -peligro- del bien jurídico tutelado. En efecto, la acción debe concretarse en la destrucción, inutilización, paralización, interrupción o daño de instalaciones, medios o elementos. Se establecen figuras agravadas si, además, se diere 
muerte a alguna persona o se le infirieren lesiones graves o de otro tipo o si el hecho se ejecutare en tiempo de guerra.

c) Las instalaciones, medios o elementos afectados pueden referirse tanto servicios públicos o de utilidad pública como a actividades industriales, mineras, agrícolas, comerciales, de comunicación, de transporte o de distribución de naturaleza privada.

d) Las penas son las mismas que para la figura anterior.

\section{B) Hurto famular}

Se trata de formas agravadas de hurto tipificadas en el art. 447 No 1 y No 2 CP respecto de las cuales podrá aplicarse la pena inmediatamente superior en grado.

Las diferencias con la figura general vienen dadas por la exigencia de un sujeto activo calificado, el trabajador dependiente -"dependiente, criado o sirviente asalariado; "obrero, oficial o aprendiz" o trabajador habitual-y por un elemento locativo, conforme al cual el hurto ha de cometerse en:

- "en la casa en que sirve o bien en aquella a que lo hubiere llevado su amo o patrón" (artículo 447 No 1 CP); o

- "en la casa, taller o almacén de su maestro o de la persona para quien trabaja” o en la casa donde trabaja habitualmente (art. 447 No 2 CP).

\subsubsection{Delitos contra el patrimonio de los trabajadores}

\section{A) Apropiación indebida de cotizaciones}

El art. 13 de la Ley 17.322 -Normas para la cobraniza de cotizaciones, aportes y multas de las instituciones de la Seguridad Social- señala que "...se aplicarán las penas del artículo 467 del Código Penal al que en perjuicio del trabajador o de sus derechohabientes se apropiare o distrajere el dinero proveniente de las cotizaciones que se hubiere descontado de la remuneración del trabajador".

a) Es un tipo específico de apropiación indebida, puesto que replica la estructura del art. 470 No 1 CP. Como en el tipo general, el objeto material de la acción -el dinero proveniente de las cotizaciones- se encuentra ya en manos del agente, en virtud de un negocio jurídico válido y preexistente -el contrato de trabajo-; el abuso de su parte radica en que con posterioridad se apropia unilateralmente de ese bien e infringe la obligación de restituirlo, causando así un perjuicio al sujeto pasivo" ${ }^{3}$ "El delito se caracteriza, entonces, porque el agente, con voluntad unilateral, altera la tenencia legítima que inicialmente tenía sobre la cosa, transformándola en una propiedad ilegítima

\footnotetext{
${ }^{3}$ Creus, citado por Garrido, M. Derecho Penal. Parte especial. Tomo IV -4a edición-. Santiago: Editorial Jurídica de Chile, 2008 , p. 373.
} 
al incorporarla dolosamente -dolo subsequens- a su patrimonio, con clara violación de la confianza que normalmente respalda esa clase de negocios o acuerdos"4.

Hay con todo una diferencia respecto de la figura general en la apropiación indebida de cotizaciones, que la justifica como figura especial, porque el trabajador no hace una entrega voluntaria de su remuneración al empleador, sino que este, jurídicamente obligado a pagársela, retiene los porcentajes correspondientes a las cotizaciones de cargo del trabajador, pero en lugar de enterarlas en los órganos de la Seguridad Social, como lo obliga la ley, se las apropia o las distrae.

b) El objeto material de la acción son los dineros correspondientes a las cotizaciones de cargo del trabajador: Pensiones - cotización a AFP/IPS-, salud -cotización a ISAPRE/ FONASA-, seguro de cesantía -cotización a AFC-. La cotización adicional para el Seguro de Invalidez y Sobrevivencia $-1 \%$ aprox. de remuneración imponible- pasó a ser de cargo del empleador a partir del 1.7.2009 respecto de aquellos empleadores con 100 o más trabajadores -con menos, a parir de: 01.07.2011-.

c) Pena: Presidio menor y multa -vid. artículo $467 \mathrm{CP}-$.

\section{B) Simulaciones contractuales}

El empleador "que simule la contratación de trabajadores a través de terceros" o "utilice cualquier subterfugio, ocultando, disfrazando o alterando su individualización o patrimonio [...] que tenga como resultado eludir el cumplimiento de obligaciones laborales y previsionales..." es sancionado administrativamente por el artículo $507 \mathrm{CT}$.

Estas conductas pueden dar lugar a los delitos del art. 466 inciso final o del artículo 471 No 2 del CP.

ETCHEBERRY observa que se trata de fraudes impropios porque:

“aun cuando la expresión 'contrato simulado' pudiera hacer pensar en los fraudes por engaño, la verdad es que esta figura no requiere necesariamente que se engañe a nadie. Se trata solo de crear una apariencia de negocio jurídico que en la realidad de las cosas no existe o es diferente. Pero las partes no buscan provocar un error en nadie en particular, ni determinar a través de ello una prestación patrimonial. Buscan solamente la creación de un aparato externo que justifique una situación que se desea mantener oculta o cuyos efectos se quieren evitar"5.

El inciso final del artículo 466 del CP, castiga al deudor no dedicado al comercio que otorgare, en perjuicio de sus acreedores, contratos simulados. "El bien jurídico protegido es la facultad de los acreedores para exigir que el deudor mantenga bienes suficientes donde hacer efectivos sus derechos cuando corresponda, es evitar el peligro de que quede en insolvencia" 6 .

\footnotetext{
${ }^{4}$ MUÑOZ CONDE, citado por Ibid.

${ }^{5}$ ETCHEBERRY, A. op. cit. (n. 2), p. 442.

${ }^{6}$ GARRIDO, M. op. cit. (n. 3), p. 307.
} 
a) Sujeto activo calificado: deudor no comerciante que tiene acreedores por deudas dinerarias.

b) El tipo objetivo lo constituye la acción de otorgar un contrato simulado, "y por tal se entiende aquel que es mendaz en cuanto a la manifestación de voluntad del deudor"7. Es un delito de mera actividad. No exige la salida efectiva de bienes del patrimonio del deudor ni un perjuicio actual a los acreedores. Es un tipo de peligro.

c) El tipo incluye un elemento subjetivo: la finalidad de perjudicar al o los acreedores. "Ese el alcance de la expresión en perjuicio de los acreedores que emplea el art. 466" 8 .

d) Pena: Presidio menor en cualquiera de sus grados.

$\mathrm{El}$ art. $471 \mathrm{CP}$ castiga al "que otorgare en perjuicio de otro un contrato simulado".

a) Según GARRIDO MONTT es un delito de sujeto plural, "de autorías compartidas y necesarias" 9 . Según el citado autor "puede ser realizado por personas que no requieren tener una calidad especial o particular, salvo que uno de ellos tenga una vinculación juridica, en alguna forma, con el tercero al que se pretende perjudicar con el falso contrato..."10.

b) El tipo objetivo es otorgar un contrato simulado. ETCHEBERRY advierte que:

"el otorgamiento de contrato simulado no es lo mismo que la simulación de un otorgamiento de contrato -que bien pudiera constituir estafa-. Esto es, no se finge otorgar un contrato, sino que se lo otorga efectivamente, pero con una de estas circunstancias: 1) Se crea así la apariencia de un acto jurídico cuando en realidad no ha existido ninguno, o 2) Se crea la apariencia de un determinado acto jurídico cuando en realidad las partes han entendido celebrar otro. Para ello es necesario que el contrato fingido se otorgue con los requisitos y solemnidades propios de la naturaleza del acto que se simula celebrar, y que se haga una declaración de voluntad no real, conscientemente y de concierto por los contratantes" 11 .

Se trata de un tipo de resultado. GARRIDO MONTT, señala que "mayoritariamente la doctrina estima que para que se consume el delito, debe efectivamente causarse un perjuicio a terceros...". Para POLITOFF, MATUS y RAMf́REZ, el perjuicio no elemento del tipo, sino condición objetiva de punibilidad lo cual excluye la posibilidad de castigo de este delito a título de tentativa o frustración ${ }^{12}$. Por su parte, ETCHEBERRY

7 Ibid.

${ }^{8}$ GARRIDO, M. op. cit. (n. 3), p. 308.

${ }^{9}$ GARRIDO, M. op. cit. (n. 3), p. 395.

10 Ibid.

11 ETCHEBERRY, A. op. cit. (n. 2), p. 443.

12 Politoff, S.; MATUS, J.P. y RAMf́Rez, C. Lecciones de Derecho penal chileno. Parte especial. Santiago: Editorial Jurídica de Chile, 2006, p. 463. 
Claudio Palavecino Cáceres y Carlos Poblete Jiménez / Apuntes sobre derecho penal del trabajo

explica que "este perjuicio debe consistir en la lesión de un derecho efectivamente existente, real o personal, de que es titular un tercero" 13 .

c) Pena: Presidio o relegación menores en sus grados mínimos o multa. 3.- Delitos contra la normalidad de las actividades nacionales.

\subsection{Paralizaciones Ilegales}

\section{A) De los trabajadores}

En el Título IV "Delitos contra la normalidad de las actividades nacionales", el artículo 11 prescribe que:

"Toda interrupción o suspensión colectiva, paro o huelga de los servicios públicos o de utilidad pública, o en las actividades de la producción, del transporte o del comercio, producido sin sujeción a las leyes y que produzcan alteraciones del orden público o perturbaciones en los servicios de utilidad pública o de funcionamiento legal obligatorio o daño a cualquiera de las industrias vitales, constituye delito, y será castigado con presidio o relegación menores en sus grados mínimo a medio.

"En la misma pena incurrirán los que induzcan, inciten, o fomenten alguno de los actos ilícitos a que se refiere el inciso anterior. En tiempo de guerra externa la pena será la de presidio o relegación menores en su grado medio a presidio o relegación mayores en su grado mínimo".

Cabe destacar algunos elementos de la conducta típica:

a) Comprende tanto al inductor, instigador o promotor como al ejecutor del hecho y no existe un sujeto activo calificado, de modo que cualquier persona imputable puede incurrir en ella;

b) Es un tipo material o de resultado y, además, un delito de lesión, pues la acción debe concretarse en un determinado resultado típico y se exige una afectación real y no meramente potencial (peligro) del bien jurídico tutelado. En efecto, la interrupción o suspensión colectiva, paro o huelga debe producir:

- alteraciones del orden público;

- perturbaciones en los servicios de utilidad pública o de funcionamiento legal obligatorio; $o$

- daño a cualquiera de las industrias vitales.

c) El objeto de la acción típica puede ser tanto los servicios públicos o de utilidad pública como las actividades de la producción, del transporte o del comercio.

d) Además el tipo contiene un elemento normativo, conforme al cual la interrupción o suspensión colectiva, paro o huelga, solo será típica si se ejecuta "sin sujeción a las leyes".

13 ETCHeberRy, A. op. cit. (n. 2), p. 443. 
Respecto de la huelga, nuestro ordenamiento jurídico solo la reconoció como derecho en el marco del procedimiento de negociación colectiva reglado y, además, con una serie de restricciones para su ejercicio. En nuestro modelo normativo laboral, más algunas disposiciones penales vigentes a la fecha, la huelga se encuentra en tres estados: huelga en la negociación colectiva, a la cual se le considera derecho, bajo los requisitos y las limitaciones que establece la ley. Fuera de la negociación colectiva reglada, la huelga constituiría una falta disciplinaria, por lo que tendría efectos contractuales. Además, también puede constituir un delito al tipificarse la figura "de interrupción o suspensión colectiva, paro o huelga", que contempla el citado artículo 11 de la Ley sobre Seguridad Interior del Estado.

Los tribunales de nuestro país han señalado, respecto a la huelga con infracción a la Ley de Seguridad del Estado, que ella “...está concebida en nuestra legislación dentro de las etapas de la Negociación Colectiva, de modo que cualquiera otra que se realice tiene el carácter de ilícito en los términos señalados por el artículo 11 de la ley 12.927 sobre Seguridad del Estado, que castiga a los que induzcan, inciten o fomenten a alguno de los ilícitos"14.

En este mismo fallo, la Excma. Corte Suprema alude al considerando quinto de la sentencia de la Corte de Apelaciones, que indica:

'De esta forma, pueden existir huelgas lícitas e ilícitas. En nuestro país, la Constitución de 1980 implícitamente reconoce la huelga como un derecho y solo la prohíbe para los funcionarios del Estado y de las municipalidades y también para aquellas personas que trabajen en corporaciones o empresas, cualquiera que sea su naturaleza, finalidad o función, que atiendan servicios de utilidad pública o cuya paralización causa grave daño a la salud, a la economía del país, al abastecimiento de la población o a la seguridad nacional, debiendo establecer la ley los procedimientos para determinar las corporaciones o empresas cuyos trabajadores estarán sometidos a esa prohibición que establece el inciso final del $\mathrm{N}^{\circ} 16$ del artículo 19 de la referida Carta Fundamental. Entre las huelgas ilícitas puede darse el caso de algunas que tengan carácter delictual y así ocurre con las tipificadas en el inciso $1^{\circ}$ del artículo 11 de la ley $\mathrm{N}^{\circ}$ 12.927."

La huelga o paralización colectiva de trabajadores se realiza sin sujeción a las leyes:

a) Cuando se realiza fuera del procedimiento de negociación colectiva reglada (artículo 314 bis $\mathrm{C}$ inciso $1^{\circ} \mathrm{CT}$ );

\footnotetext{
14 Considerando Quinto, Excma. Corte Suprema, sentencia de 17 de agosto de 1988, Rol 7244, Caratulado "Ministerio del Interior con Manuel Bustos Huerta; Arturo Martínez Molina; Moisés Labraña Mena".
} 
Claudio Palavecino Cáceres y Carlos Poblete Jiménez / Apuntes sobre derecho penal del trabajo

b) cuando se realiza dentro un procedimiento de negociación colectiva reglada pero incumpliéndose cualquiera de los requisitos legales que establece dicho procedimiento para su votación ${ }^{15}$, aprobación ${ }^{16}$, y ejecución ${ }^{17}$;

c) cuando se efectúa por trabajadores que tienen prohibición de declarar la huelga ${ }^{18}$.

\begin{abstract}
15 Oportunidad legal: El día de la votación debe estar comprendido dentro de los 5 últimos días de vigencia del contrato colectivo o del fallo arbitral anterior. De no existir estos instrumentos, el día de la votación debe estar comprendido dentro de los 5 últimos días de un total de 45 ó 60 -según se trate del procedimiento de negociación dentro de la empresa o del procedimiento de negociación supraempresas, respectivamente-contados desde la presentación del proyecto.
\end{abstract}

Requisitos previos a la votación:

a) Que la negociación no esté sujeta a arbitraje obligatorio.

b) Que las partes no hubieren convenido en someter el asunto a arbitraje.

c) Que la votación sea convocada a lo menos con 5 días de anticipación.

d) El empleador deberá informar a todos los trabajadores interesados su última oferta y -si esta no fuere coincidente con la respuesta dada a proyecto de contrato colectivo- deberá acompañar una copia de la última oferta a la Inspección del Trabajo, con una anticipación de a lo menos 2 días al plazo de cinco, dentro de los cuales se debe verificar la votación. Para este efecto, entregará un ejemplar a cada trabajador o exhibirá dicha proposición en lugares visibles de la empresa. Todos los gastos correspondientes a esta información serán de cargo del empleador.

Requisitos de la votación: La votación deberá efectuarse en forma personal, secreta y en presencia de un ministro de fe.

Tendrán derecho a participar en la votación todos los trabajadores de la empresa respectiva involucrados en la negociación.

Los votos serán impresos y deberán emitirse con la expresión "última oferta del empleador", o con la expresión "huelga", según sea la decisión de cada trabajador.

El día que corresponda proceder a la votación no podrá realizarse asamblea alguna en la empresa involucrada en aquella.

Ahora bien, cuando la votación no se hubiere llevado a efecto por causas ajenas a los trabajadores estos tendrán un plazo de 5 días para proceder a ella.

${ }^{16}$ La huelga deberá ser acordada por la mayoría absoluta de los trabajadores de la respectiva empresa, involucrados en la negociación.

17 Plazo para hacerla efectiva: Dispone el art. 374 CT que, acordada la huelga, esta deberá hacerse efectiva al inicio de la respectiva jornada del tercer día siguiente a la fecha de su aprobación. Este plazo podrá prorrogarse, por acuerdo de las partes, por otros 10 días.

Además es preciso tener presente que, dentro de las 48 horas siguientes de acordada la huelga, cualquiera de las partes podrá solicita al Inspector del Trabajo la interposición de sus buenos oficios, para facilitar el acuerdo entre ellas. El Inspector dispone de 5 dias hábiles para conseguir que las partes lleguen a un acuerdo. Si fracasa, la huelga deberá hacerse efectiva al inicio del día siguiente hábil, salvo que las partes acordaren que continúe su gestión por un lapso de hasta 5 días, prorrogándose por este hecho la fecha en que la huelga debe hacerse efectiva.

Modo en que se concretiza la huelga: El art. 374 inciso $3^{\circ} \mathrm{CT}$ señala que "se entenderá que no se ha hecho efectiva la huelga en la empresa si más de la mitad de los trabajadores de esta, involucrados en la negociación, continuaren laborando en ella". Leído sensu contrario, la huelga se ejecuta o concretiza como acto colectivo si se abstiene de laborar en la empresa, a lo menos, la mitad de los trabajadores involucrados en la negociación. Del precepto citado se colige que nuestro ordenamiento legal concibe la huelga según el concepto clásico y restrictivo de cesación de labores con abandono del centro de trabajo.

Para estos efectos, en aquellas empresas en que el trabajo se realice mediante sistema de turnos, el quórum necesario para hacer efectiva la huelga se calculará sobre la totalidad de los trabajadores involucrados en la negociación y cuyos turnos se inicien al tercer día siguiente al de la aprobación de la huelga. Así, por ejemplo, en una empresa en que negocian colectivamente 500 trabajadores, si el turno que se inicia el tercer día de la aprobación de la huelga comprende 100 trabajadores involucrados en la negociación, se entenderá materializada la huelga si se abstienen de trabajar 50 de ellos.

${ }^{18}$ Recordemos que la propia Constitución Política señala en su art. 19 No 16 inc. final que no podrán declararse en huelga los funcionarios del Estado ni de las municipalidades.

Agrega que tampoco podrán hacerlo las personas que trabajen en corporaciones o empresas, cualquiera que sea su naturaleza, finalidad o función, que atiendan servicios de utilidad pública o cuya paralización cause grave daño a la salud, a la economía del país, al abastecimiento de la población o a la seguridad nacional.

Finalmente, encomienda a la ley establecer los procedimientos para determinar las corporaciones o empresas cuyos trabajadores estarán sometidos a esta prohibición.

Pues bien, el precepto legal que viene a concretizar este último mandato constitucional es el art. 384 del Código del Trabajo. 


\section{B) Del empleador}

El artículo 12 Ley No 12.927 establece que:

"los empleadores o patrones que declaren el lock out o que estuvieren comprometidos en los delitos contemplados en el artículo 11 , serán castigados con la pena de presidio o relegación menores en su grado mínimo a medio y multas de cinco sueldos vitales mensuales a diez sueldos vitales anuales.

En tiempo de guerra externa la pena será de presidio o relegación menores en su grado medio a presidio o relegación mayores en su grado mínimo".

El Código del Trabajo contempla el lock out lícito, el cual, conforme al inciso $2^{\circ}$ del artículo $375 \mathrm{CT}$ es "el derecho del empleador, iniciada la huelga, a impedir temporalmente el acceso a todos los trabajadores a la empresa o predio, o al establecimiento". Sin embargo, dado que el tipo del art. 12 no contiene un elemento normativo como sucede con la huelga, de manera que el ejercicio del lock out legítimo no elimina la tipicidad, sino la antijuridicidad de la conducta.

El delito podría configurarse cuando el empleador que cierra su empresa de manera repentina y permanente. O bien cuando el lock out es ofensivo, esto es, el que pretende anticiparse a.la estrategia de los trabajadores y que se concretiza antes de la realización de la huelga, pues como advierte MACCHIAVELLO "el lock-out no puede tener lugar fuera de la huelga" ${ }^{19}$. De acuerdo con el inc. $1^{\circ}$ del artículo 376 CT, el lock out, sea total o parcial, solo podrá ser declarado por el empleador en dos situaciones:

a) Si la huelga afectare a más del 50\% del total de trabajadores de la empresa o del establecimiento en su caso; o

b) Si la huelga significare la paralización de actividades imprescindibles para su funcionamiento, cualquiera fuere en este caso el porcentaje de trabajadores en huelga.

En su primer inciso, esta disposición reitera lo ya señalado por la Carta Fundamental, al prescribir que no podrán declarar la huelga los trabajadores de aquellas empresas que:

a) Atiendan servicios de utilidad pública, o

b) Cuya paralización por su naturaleza cause grave daño a la salud, al abastecimiento de la población, a la economía del paŕs o a la seguridad nacional.

En su inciso segundo precisa esta última circunstancia en el sentido que, para entender que se causa grave daño a los bienes jurídicos mencionados en la letra b), será necesario que la empresa de que se trate comprenda parte significativa de la actividad respectiva del país, o que su paralización implique la imposibilidad total de recibir un servicio para un sector de la población.

$\mathrm{Si}$ en estos casos no se logra acuerdo directo entre las partes en el proceso de negociación colectiva, procederá el arbitraje obligatorio.

En su inciso final, el art. 384 establece el procedimiento para determinar si la empresa se encuentra comprendida en alguna de las situaciones que impiden la huelga. El precepto señala que la calificación de esta circunstancia será efectuada dentro del mes de julio de cada año, por resolución conjunta de los Ministerios del Trabajo y Previsión Social, Defensa Nacional y Economía, Fomento y Reconstrucción.

${ }^{19}$ MACCHIAVEllo, G. Derecho colectivo del trabajo: teoría y análisis de sus normas. Santiago: Editorial Jurídica de Chile, 1989, p. 464. 
El derecho al cierre patronal tiene un carácter reactivo o defensivo respecto de esta medida " $\mathrm{y}$ tiene por objeto presionar a los huelguistas y a los que en general presentaron el proyecto de negociación por medio de sus compañeros de trabajo, que no fueron parte de la huelga, a fin de que pongan término a ella y acepten la última oferta patronal"20.

También pudiera dar lugar al delito el lock out intempestivo, habida cuenta que el artículo 375 inciso $1^{\circ} \mathrm{CT}$ establece la oportunidad de su ejercicio y su duración ${ }^{21}$.

\subsection{DELITOS CONTRA LA FE PÚBLICA}

El artículo 509 CT señala que "las personas que incurran en falsedad en el otorgamiento de certificados, permisos o estado de salud, en falsificación de estos, o en uso malicioso de ellos, serán sancionadas con las penas previstas en el artículo 202 del Código Penal".

a) No hay sujeto activo calificado.

b) Tipo con pluralidad de hipótesis. Incurrir en falsedad, vale decir mentir en el otorgamiento del certificado -falsedad ideológica-; o bien falsificarlo -falsedad material- no fue otorgado por quien dice o fue adulterado en su contenido; o bien usarlo maliciosamente, vale decir, a sabiendas de que es falso.

c) Objeto material: certificado, vale decir, documentos en que se da por cierto algo. En materia laboral se requiere un certificado médico de aptitud para trabajar en industrias o faenas peligrosas o insalubres -artículo $186 \mathrm{CT}$-; la trabajadora embarazada debe exhibir a su empleador certificado médico o de matrona donde conste su estado si por ignorancia del mismo hubiere sido desvinculada a fin de que se la reincorpore-artículo 201, inciso $4^{\circ} \mathrm{CT}$-; certificado de estado civil de los parientes inmediatos del trabajador para percibir remuneraciones pendientes a su muerte -artículo $60 \mathrm{CT}$-, etc.

d) Pena: reclusión menor en su grado mínimo a medio y multa de 6-10 UTM.

\subsection{DELITOS CONTRA LA LIBERTAD SEXUAL: ACOSO SEXUAL}

De conformidad al artículo 2 , inciso $2^{\circ}$, CT se entiende por acoso sexual "el que una persona realice en forma indebida, por cualquier medio, requerimientos de carácter sexual, no consentido por quien lo recibe y que amenacen o perjudiquen su situación laboral o sus oportunidades en el empleo".

El tipo parece dirigirse únicamente a la protección del bien jurídico de la libertad sexual, entendida como "aquella parte de la libertad referida al ejercicio de la propia sexua-

\footnotetext{
${ }^{20}$ Ibid.

21 Acordada la huelga y una vez que esta se hubiere hecho efectiva, el empleador podrá declarar el lock-out o cierre temporal de la empresa, el que podrá ser total o parcial. Dispone el artículo 375 inciso final CT que el lock-out no podrá extenderse más allá del trigésimo día, a contar de la fecha en que se hizo efectiva la huelga o del día del término de la huelga, cualquiera ocurra primero.
} 
lidad y, en cierto modo, a la disposición del propio cuerpo" 22 . A esta conclusión lleva, por una parte, el que la acción típica consista en realizar "requerimientos de carácter sexual", vale decir, solicitar favores de tal naturaleza y, por otra, la exigencia que tales requerimientos no sean consentidos por su destinatario. Insisto, pues, en que, tal como está redactado, el tipo aparece estructurado claramente como un atentado contra un bien jurídico específico: la libertad sexual de la víctima. Por tanto, no veo cómo se pueda extraer de la norma el pródigo listado de bienes jurídicos que ofrecen los comentaristas nacionales ${ }^{23}$. El tipo exige, además, la producción de un resultado típico, el perjuicio de la situación laboral o de las oportunidades en el empleo de la víctima o, cuando menos, la creación de un peligro o de una amenaza de tal perjuicio. Resultado que parece remitirnos al acoso coercitivo o quid pro quo y a la existencia de un sujeto agente idóneo para producir aquellas consecuencias. De modo que el acoso sexual exigiría un sujeto activo calificado, a saber: el empleador o sus representantes en la empresa.

No obstante, se ha dicho, acaso impensadamente, que "en el caso chileno la ley no deja margen de duda: el acoso sexual puede ser cometido por el empleador -acoso vertical- o un compañero de trabajo, ya sea uno del mismo o inferior plano jerárquico -acoso horizontal o ambiental-"24. Tal afirmación resulta asaz sorprendente, puesto que no se compadece con la recién examinada redacción del tipo del artículo $2^{\circ}$ inciso $2^{\circ} \mathrm{CT}$ que solo tipifica el acoso sexual coercitivo o de intercambio, dejando, en principio, como conductas atípicas el requerimiento sexual efectuado por quien no tiene poder de influir en las condiciones $\mathrm{u}$ oportunidades de trabajo de la víctima -acoso sexual horizontal- $\mathrm{y}$ aquellas otras formas de acoso que no buscan la obtención de favores sexuales. Por tanto, para ampliar la extensión del tipo a otros sujetos activos, distintos del empleador y de sus representantes, es preciso un esfuerzo hermenéutico. En primer lugar, hay que concordar el artículo $2^{\circ}$ inciso $2^{\circ} \mathrm{CT}$ con el art. 160 No 1 letra b) CT; esta última disposición permite sancionar con el despido disciplinario al trabajador que incurre en "conductas de acoso sexual". Aquí hay un primer indicio de que tales conductas pueden ser cometidas por sujetos distintos del empleador. Con todo, esta norma nos reconduce a la definición del artículo $2^{\circ}$ inciso $2^{\circ} \mathrm{CT}$ y a la exigencia del tipo en orden a que la víctima vea amenazada o perjudicada "su situación laboral o sus oportunidades en el empleo". Volvemos, pues, al punto de inicio: habría acoso sexual laboral solo cuando el sujeto activo tiene el poder de generar el efecto que pide la norma, vale decir, cuando el acosador es el empleador o un trabajador que, en su nombre, ejerce facultades de organización, de control o de disciplina dentro de la empresa. ¿Cómo se rompe este círculo vicioso? Entendiendo que el resultado de "perjuicio de la situación laboral" de la víctima no se refiere solo al menoscabo de las condiciones de trabajo que son resorte del empleador o de sus representantes, sino que la exigencia del tipo se satisface también con un resultado más difuso: el sentimiento de incomodidad que provoca en la víctima

\footnotetext{
22 MuÑoz CONDE et al. Citados por DÉl Rey GuANTER, S. "Acoso sexual y relación laboral", en: Relaciones Laborales, tomo I, 1993, p. 247, nota 73.

${ }^{23}$ Cfr. CAAmaño Rojo, E. et al. El acoso sexual en la Empresa. Análisis de la Ley 20.005. Santiago: LexisNexis, 2005, pp. 21 y ss.

${ }^{24}$ Lizama, L. y UGARTE, J.L. Nueva Ley de Acoso Sexual, LexisNexis, Santiago de Chile, 2005, p. 14. Aunque más adelante -p. 16- los autores reconocen "las dudas que podría generar" la "redacción literal" del artículo $2^{\circ}$ inciso $2^{\circ}$ CT.
} 
la reiteración de propuestas sexuales indeseables de uno de sus pares, lo cual vendría a deteriorar su "situación laboral", en sentido amplio ${ }^{25}$.

Ahora bien, lo que no encaja de ningún modo dentro del tipo del artículo $2^{\circ} \mathrm{CT}$ es el acoso no vinculado a un requerimiento o solicitación sexual. La circunstancia de que un trabajador se vea confrontado, sin consentir ni poder sustraerse, a un ambiente laboral cargado de obscenidad verbal o gráfica no configura acoso sexual en Chile, porque la mera obscenidad no está tipificada como acoso sexual en el precepto citado. Por tanto, las expresiones o gestos soeces reiterados contra la víctima, la exposición de material pornográfico o incluso la realización de actos de exhibicionismo, por poner algunos ejemplos, no configuran el ilícito específico de acoso sexual, si no conllevan una invitación dirigida a quien los padece de satisfacer una pretensión o un deseo sexual. Por más que el art. $2^{\circ}$ inc. $2^{\circ} \mathrm{CT}$ hable de amenaza o perjuicio "de la situación laboral" de la víctima y por más que la doctrina científica y administrativa incluya en esta expresión "la creación de un ambiente hostil y humillante de trabajo" ${ }^{26}$, la vinculación causal que hace el tipo con una solicitud previa torna atípicas buena parte de las conductas que configuran el acoso sexual ambiental ${ }^{27}$.

\subsubsection{Posible sanción penal}

POLITOFF, MATUS y RAMírez, siguiendo a de RIVACOBA, opinan que el acoso sexual cabe perfectamente en las previsiones del Código Penal, principalmente en el instituto de las amenazas condicionales, particularmente las referidas a un mal no constitutivo de delito -artículo 297 del CP_28.

Entre los delitos contra la libertad sexual se observan dos figuras que permitirían sancionar algunas formas de acoso sexual a menores:

- El estupro por abuso de una relación de dependencia de la víctima, que castiga el acceso carnal, por vía vaginal, anal o bucal respecto de un menor de 18 años y mayor de 14 y en que, conforme al art. 363 No $2^{\circ} \mathrm{CP}$, la relación de dependencia entre el sujeto activo y la víctima puede ser una relación laboral.

- Los abusos sexuales del art. 366 inciso 20 CP que castiga los actos de significación sexual y de relevancia realizados mediante contacto corporal con la víctima mayor de 14, o sin contacto corporal pero afectado sus genitales, ano o la boca, cuando se abusa de una relación de dependencia de naturaleza laboral.

\footnotetext{
${ }^{25}$ En igual sentido, LizamA, L. y Ugarte, J.L. op. cit. (n. 24), p. 16. Vid., también, Dictamen D.T. Nº $1133 / 36$ de 21 de marzo de 2005.

26 Ibid.

27 Vid. Palavecino, C. "El nuevo ilícito de acoso sexual en el derecho del trabajo chileno", en: Revista de Derecho vol. 19, $N^{\circ}$ 1. Valdivia: Universidad Austral de Chile, 2006, pp. 105-123.

28 PalaVeCino, C. op. cit. (n. 27), p. 109 y ss.
} 


\section{BIBLIOGRAFÍA}

Bullemore, V. y MaCkinnon, J. Curso de Derecho Penal. Tomo III, Parte Especial. Santiago: LexisNexis, 2007.

CAAmaño Rojo, E. et al. El acoso sexual en la Empresa. Análisis de la Ley 20.005. Santiago: LexisNexis, 2005.

DEL REY GUANTER, S. “Acoso sexual y relación laboral”, en: Relaciones Laborales, tomo I, 1993, p. 247.

ETCheberry, A. Derecho Penal, parte especial. Tomo III. Santiago: Editorial Jurídica de Chile, 1997.

Garrido, M. Derecho Penal. Parte especial. Tomo IV -4a edición-. Santiago: Editorial Jurídica de Chile, 2008.

LizAma, L. y Ugarte, J.L. Nueva Ley de Acoso Sexual, LexisNexis, Santiago de Chile, 2005.

MaCChiavello, G. Derecho colectivo del trabajo: teoria y análisis de sus normas. Santiago: Editorial Jurídica de Chile, 1989.

OrTIZ SCHNDLER, Enrique. El Derecho Penal Laboral. Tesis. Santiago: Universidad de Chile, Facultad de Derecho, 1982.

PalaVecino, C. "El nuevo ilícito de acoso sexual en el derecho del trabajo chileno", en: Revista de Derecho vol. 19, $\mathrm{N}^{\circ} 1$. Valdivia: 2006, pp. 105-123.

Politoff, S.; Matus, J.P. y RamíRez, C. Lecciones de Derecho penal chileno. Parte especial. Santiago: Editorial Jurídica de Chile, 2006. 